\title{
ANALYSIS OF CONTROL QUALITY OF AIRCRAFT LATERAL MOTION DURING APPROACH WITH THE USE OF DIFFERENT CONTROL LAWS
}

\section{G. Kopecki}

Rzeszow University of Technology, Dep. of Avionics and Control, Al. Powstancow W-wy 8, 35-959 Rzeszow, Poland. E-mail: gkopecki@prz.edu.pl

Received 1412 2005, accepted 07092006

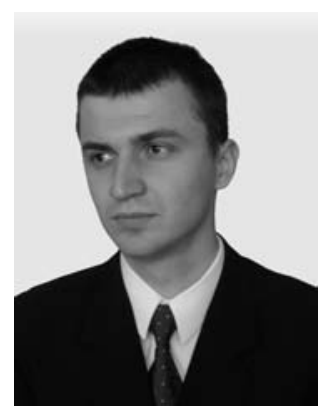

\section{Grzegorz KOPECKI, Assistant}

Education: M. Sc. Eng. degree in Aeronautics, Rzeszow University of Technology, Faculty of Mechanical Engineering and Aeronautics. 2001 up to present: assistant at Rzeszow University of Technology, Department of Avionics and Control.

Research field: Problems of Aircraft Control.

Publications: Author and co-author of about 10 scientific articles, participant in three research projects.

Abstract. The article presents different methods of control of the lateral motion of aircraft during approach with the use of ILS-LOC. Results of computer simulations are presented. An assessment of the quality with and without cross-wind was made with the use of quality coefficients. The control laws are based on PID regulator and its modifications. Moreover, the application of the modelfollowing control in case of incomplete measurement, i.e. lack of information about the track angle, is presented. For interception, the model is used as the generator of the desired trajectory. The difference between the real and model trajectory is used for wind compensation, instead of the integration in LOC regulator. For control law synthesis for stabilization, linear quadratic regulator method was used.

The best control quality was obtained in the solution using information about the track angle and the solution using the modelfollowing control.

Keywords: aircraft control systems, aircraft approach, PID, control quality, model-following control, LQR.

\section{Introduction}

The approach is a very complicated phase of flight. During this operation, the pilot is under stress caused by the amount of information as well as psycho-physical factors. This fact has been proved by many disasters. Disasters are much more frequent during approach and landing than during other phases of flight. Automatic control of approach is therefore expected to ensure flight safety [1].

One of the most popular systems enabling automatic landing is Instrument Landing System (ILS) [2]. This paper presents the control of lateral motion during approach. It is realized through the control of angle $\varepsilon_{\mathrm{s}}$, which is the angle between the approach axis and a line connecting the localizer (LOC) and the aircraft's center of gravity (Fig 1). In this paper, it will be called angle of approach. The general control scheme is presented in figure 2 .

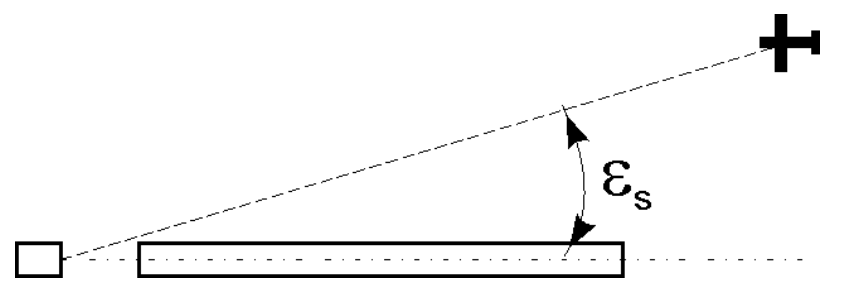

Fig 1. The $\varepsilon_{\mathrm{s}}$ angle definition

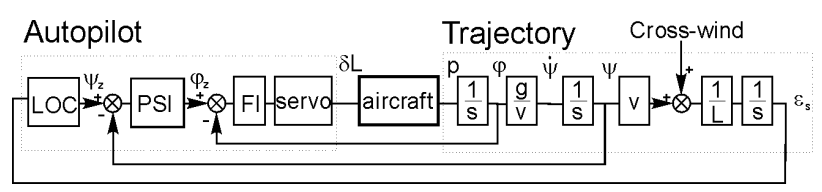

Fig 2. General ILS-LOC Approach Control Scheme, $\psi-$ heading; $\phi$ - bank angle; -roll rate $\psi_{\mathrm{z}}, \varphi_{\mathrm{z}}$-expected value; Ldistance between LOC and aircraft; $\mathrm{V}$ - aircraft velocity; $\delta \mathrm{L}-$ aileron displacement 
For synthesis of the approach control system, the methodology of control quality assessment was adopted. The following factors were taken into consideration:

$\checkmark$ assessment of the overshoot. It is essential to strive at minimum overshoot.

$\checkmark \quad$ assessment of oscillations. They can be accepted only in certain cases. Dimensionless damping ratio should be lower then 0.7 .

$\checkmark$ elimination or minimization of the trajectory flex point, which can appear as a result of a change in the control laws.

All factors are based on expert knowledge. This knowledge is the result of pilots' practice and simulation experiments.

The autopilot should control the flight in the same way a pilot does. During the first phase of approach, called interception, the aircraft usually flies with a constant heading. When it is near the axis of approach, stabilization begins.

The best control would be if the aircraft went in the desired, ideal trajectory. The ideal trajectory was calculated on a simulated approach control system. It was assumed that the heading during interception was constant, and during stabilization a PD (proportionaldifferential) LOC regulator was used. The simulated flight was without disturbances. To compare different results a performance index (1) was used:

$$
\begin{aligned}
& J=J_{1}+J_{2}+J_{3} \\
& J_{1,2,3}=\int\left(\varepsilon_{s}-\varepsilon_{m}\right)^{2} d t
\end{aligned}
$$

Where:

$J_{1}$ - performance index without disturbances,

$J_{2}, J_{3}$-performance index with right and left constant cross wind $(8 \mathrm{~m} / \mathrm{s})$

$\varepsilon_{s}$ - trajectory of the tested control system

$\varepsilon_{m}$ - trajectory of the "ideal" control system.

Time of simulation for performance index calculations was 200[s]. Moreover, in section 5 the influence of wind turbulence during stabilization was tested.

\section{Aircraft Model}

For the description of aircraft dynamics, equations (3) are usually used. Theoretically, those equations describe aircraft dynamics in all typical flight phases.

$$
\begin{aligned}
& m(\dot{U}+Q W-R V+g \sin \Theta)=X \\
& m(\dot{V}+Q U-R W+g \sin \Phi \cos \Theta)=Y \\
& m(\dot{W}+Q V-R U+g \cos \Phi \cos \Theta)=Z \\
& \dot{P} I_{x}+Q R\left(I_{z}-I_{y}\right)-(P Q+\dot{R}) I_{x z}=L \\
& \dot{Q} I_{y}+P R\left(I_{x}-I_{z}\right)+\left(P^{2}+R^{2}\right) I_{x z}=M \\
& \dot{R} I_{z}+P Q\left(I_{y}-I_{x}\right)+(Q R+\dot{P}) I_{x z}=N
\end{aligned}
$$

Where:

$U, V, W-$ components of an aircraft velocity vector in body frame,

$P, Q, R$ - components of an aircraft angular velocity vector in body frame,
$X, Y, Z$ - components of aerodynamic forces and thrust vector in body frame,

$L, M, N$ - components of moment of external forces in body frame,

$\Phi, \Theta, \Psi$-bank angle, pitch angle, yaw angle,

$I_{x}, I_{y}, I_{z}$ - aircraft moments of inertia,

$I_{x z}$ - aircraft moment of deviation.

These equations contain products of the dependent variables, some of which appear as transcendental functions; therefore they are in general nonlinear and it is impossible to solve them analytically. It is also difficult to apply numerical methods for these equations. Consequently, the linearization of these equations is usually used. During the linearization described in [3], equations of motion are divided into two groups. One of them describes longitudinal motion, the other lateral motion. The second group is presented as the equation (4).

$$
\begin{aligned}
& {\left[\begin{array}{c}
\dot{\beta} \\
\dot{p} \\
\dot{r} \\
\dot{\varphi}
\end{array}\right]=\left[\begin{array}{cccc}
Y_{v} & Y_{p} & Y_{r}-U_{0} & g \cos \Theta_{0} \\
L_{\beta}^{\prime} & L_{p}^{\prime} & L_{r}^{\prime} & 0 \\
N_{\beta}^{\prime} & N_{p}^{\prime} & N_{r}^{\prime} & 0 \\
0 & 1 & \operatorname{tg} \Theta_{0} & 0
\end{array}\right]\left[\begin{array}{l}
\beta \\
p \\
r \\
\varphi
\end{array}\right]} \\
& +\left[\begin{array}{cc}
Y_{\delta L} & Y_{\delta K} \\
L_{\delta L}^{\prime} & L_{\delta K}^{\prime} \\
N_{\delta L}^{\prime} & N_{\delta K}^{\prime} \\
0 & 0
\end{array}\right]\left[\begin{array}{c}
\delta_{L} \\
\delta_{K}
\end{array}\right]+\left[\begin{array}{c}
Y_{v g} \\
L_{v g}^{\prime} \\
N_{v g}^{\prime} \\
0
\end{array}\right] \mathbf{v}_{\mathbf{g}}
\end{aligned}
$$

and:

$$
\mathbf{r}=\dot{\psi} \cos \Theta_{0} ; \beta=\frac{\mathbf{v}}{U_{0}} ;
$$

Where:

$\beta$-increment of slide angle,

$p, r$-increment of angular aircraft velocities (bank, yaw) in body frame,

$\varphi$ - increment of aircraft bank angle,

$\delta_{L}, \delta_{K}-$ aileron and rudder deflection angle,

$\mathbf{v}_{\mathbf{g}}-$ cross-wind velocity vector.

$U_{0}-$ aircraft forward speed,

$\Theta_{0}-$ aircraft pitch angle,

$g$ - acceleration of gravity,

$\mathbf{v}$ - increment of cross-wind velocity vector in body frame.

All other values are lateral stability derivatives described in [1].

Additionally, assuming that the course of approach is zero and $\beta=0$ :

$$
\dot{\varepsilon}_{s}=\psi \cdot \frac{U_{0}}{L}
$$

The aircraft model (4), (5) was used for simulations of control systems. For the synthesis of control systems, the rolling mode can be used:

$$
\dot{\mathbf{p}}=L_{p}^{\prime} \mathbf{p}+L_{\delta L}^{\prime} \delta_{L}+L_{v}^{\prime} \mathbf{v}_{\mathbf{g}}
$$

For the synthesis of control systems, it can be assumed that: $\mathbf{v}_{\mathbf{g}}=0$. Then, assuming all initial conditions as zero 
and treating aileron angle $\delta_{L}$ as input and bank angle velocity $\mathbf{p}(\mathbf{t})$ as output, the transfer function can be calculated:

$$
G_{0 \delta L}^{p}=\frac{L_{\delta L}^{\prime}}{s-L_{p}^{\prime}}
$$

Where:

$L_{\delta L}^{\prime}, L_{\delta p}^{\prime}-$ stability derivatives, and for analyzed case: $L_{\delta L}^{\prime}=-19,5682 \frac{1}{s^{2}}, L_{p}^{\prime}=-8,3949 \frac{1}{s}$.

The transfer function (8) is used for the synthesis of control systems. For simulations, equations (4) and (5) are used. Stability derivatives are characteristic for the PZL-110 Koliber. In all control systems described, yaw angle and roll angle controllers are based on the proportional controller. Values of gains: for yaw angle controller: $\mathrm{k}_{\psi}=1.5$, for roll angle controller: $\mathrm{k}_{\varphi}=-0.5$.

\section{Classical control laws}

Classical control laws are usually based on PID regulator. In the solution presented, during interception the desired course is constant. When stabilization starts, then the control law is based on PID modified controller. Coefficients P, I, D are dependent on the distance between the aircraft and the localizer.

Integration in a PID controller causes overshoot [4]. To improve control quality, the coefficient of integration is dependent on angle $\varepsilon_{\mathrm{s}}$. Then control laws are:

For interception:

$$
\psi_{Z}=\psi_{Z 0} \cdot \operatorname{sign}\left(\varepsilon_{s}\right)+\psi_{L}
$$

For stabilization:

$$
\psi_{Z}=P \varepsilon_{s}+g\left(\varepsilon_{s}\right) \cdot I \int \varepsilon_{s} d t+D \dot{\varepsilon}_{s}+\psi_{L}
$$

Where: $g\left(\varepsilon_{s}\right)=e^{-\left(a \varepsilon_{s}\right)^{2}}, \mathrm{a}-$ constant coefficient.

This solution improves quality of control during stabilization. If the velocity of cross-wind is faster than predicted during the creation of control laws, however, then control is based on PD controller and the control error cannot be eliminated. To eliminate this disadvantage, integration is dependent on $\frac{d \varepsilon_{s}}{d t}$. Then the control laws are:

For interception:

$$
\psi_{Z}=\psi_{Z 0} \cdot \operatorname{sign}\left(\varepsilon_{s}\right)+\psi_{L}
$$

For stabilization:

$$
\psi_{Z}=P \varepsilon_{s}+k \cdot g(\dot{\varepsilon}) \cdot I \int \varepsilon_{s} d t+D \dot{\varepsilon}_{s}+\psi_{L}
$$

Where $g\left(\dot{\varepsilon}_{s}\right)=e^{-\left(a \dot{\varepsilon}_{s}\right)^{2}}$

$k$ - additional feedback loop coefficient.

Results of simulations with different control laws are shown in figure 3.

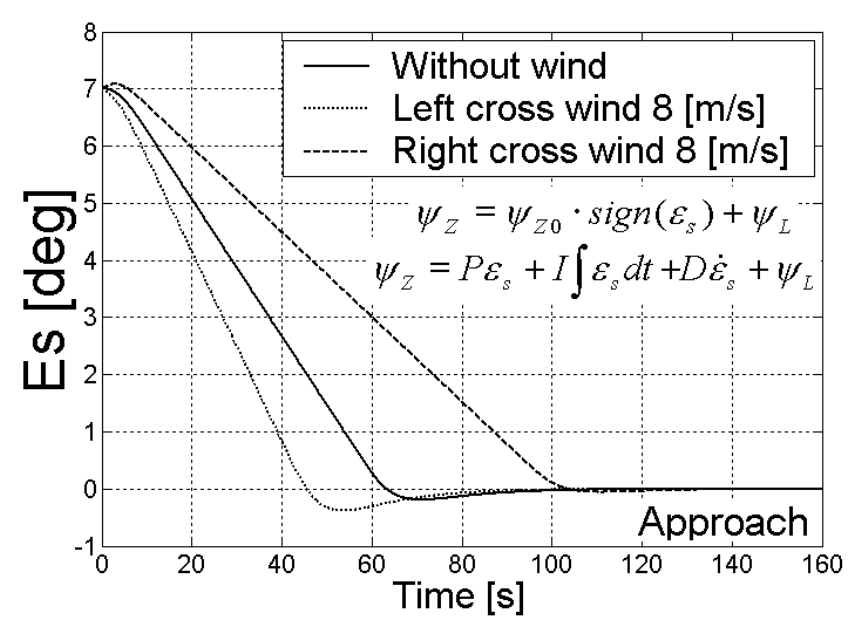

Fig 3a. Simulation results for whole approach with the use of control laws (9) for interception and based on PID for stabilization

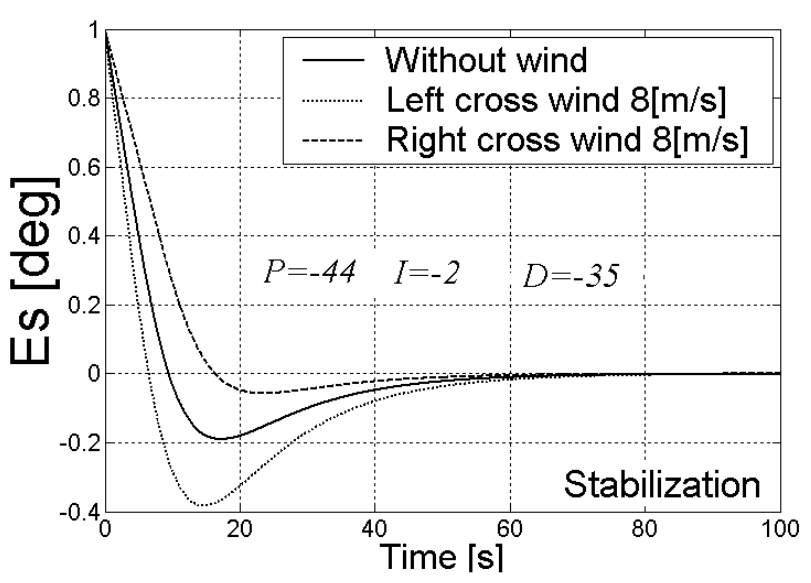

Fig 3b. Simulation results for stabilization with the use of control law based on PID

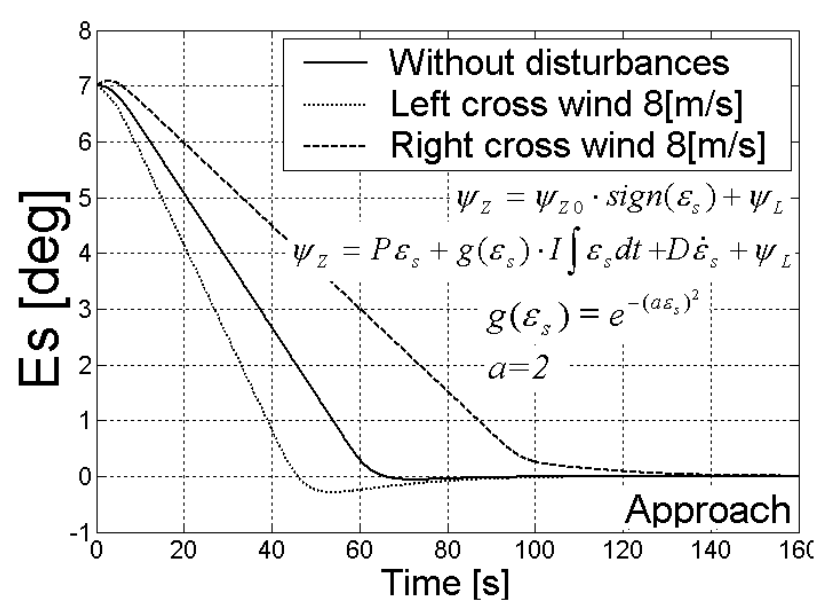

Fig 3c. Simulation results for whole approach with the use of control laws (9) and (10) 


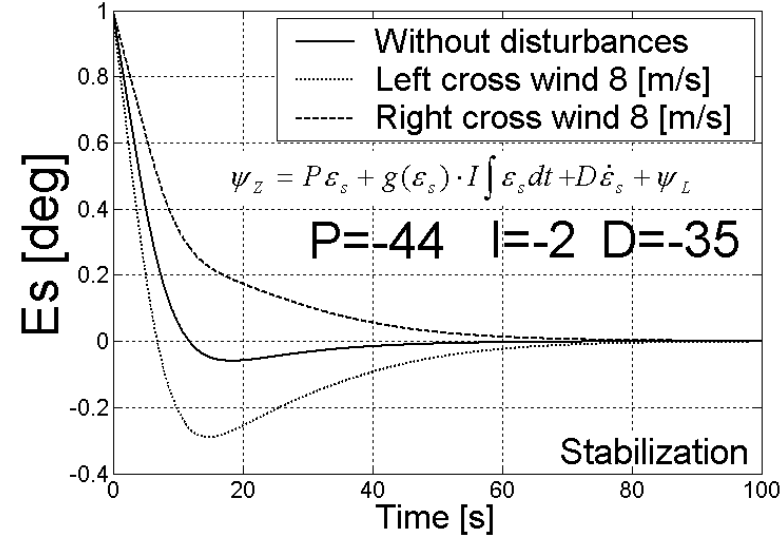

Fig 3d. Simulation results for stabilization with the use of control law (10)

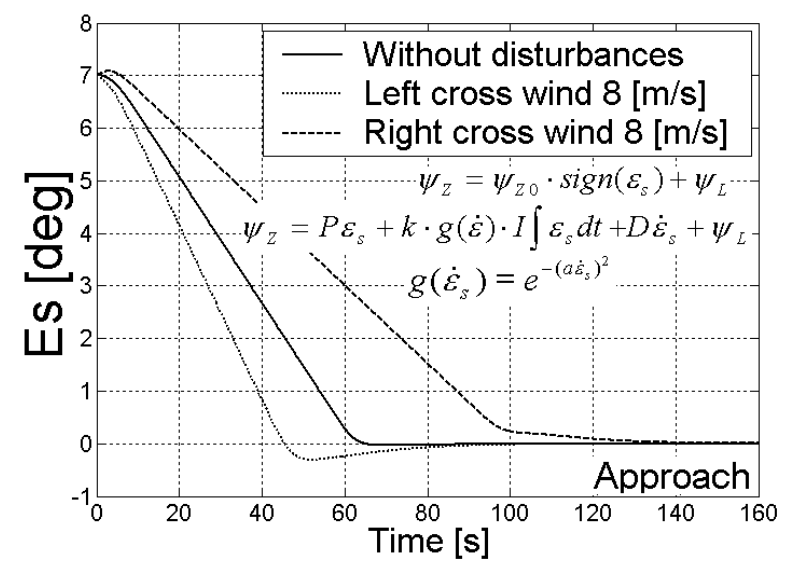

Fig 3e. Simulation results for whole approach with the use of control laws (11) and (12)

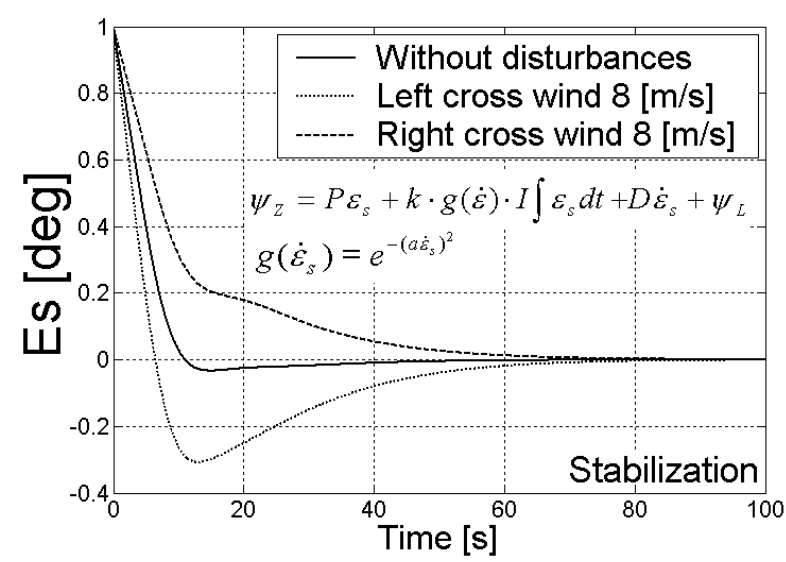

Fig 3f. Simulation results for stabilization with the use of control law (12)

Table 1 presents performance index values.

Table 1. Values of performance index

\begin{tabular}{|l|l|l|l|}
\hline Phase of flight & PID & $P(I \cdot g(\varepsilon)) D$ & $P(I \cdot g(\dot{\varepsilon})) D$ \\
\hline Stabilization & 4.014 & 3.187 & 3.259 \\
\hline Full approach & 371.4 & 368.3 & 369.5 \\
\hline
\end{tabular}

Figures 3 and table 1 show that the modification of PID regulators improves quality of regulation during stabilization. Nevertheless, during interception serious errors appear. They are caused by wind cross. If the autopilot had information about the wind cross, this information could be used for wind compensation.

Due to the wind, the track angle and heading of the aircraft are different. With information about both of them, the difference can be used as additional wind compensation. Then a control laws are:

For interception: $\quad \psi_{Z}=\psi_{Z 0} \cdot \operatorname{sign}\left(\varepsilon_{s}\right)+\psi_{L}+k_{z}$

For stabilization:

$$
\psi_{Z}=P \varepsilon_{s}+k \cdot g(\dot{\varepsilon}) \cdot I \int \varepsilon_{s} d t+D \dot{\varepsilon}_{s}+\psi_{L}+k_{z}
$$

Where:

$k_{z}=\psi-k_{d}, k_{d}-$ track angle.

Results of simulation are shown in figure 4 .

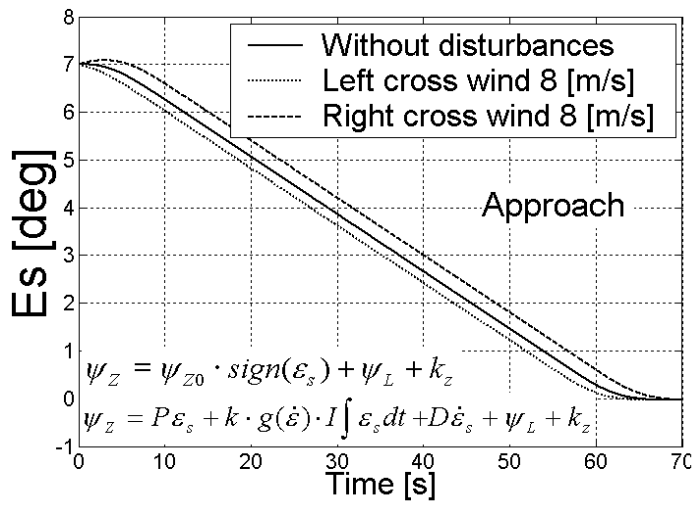

Fig 4a. Simulation results for whole approach with the use of control laws 13 and 14

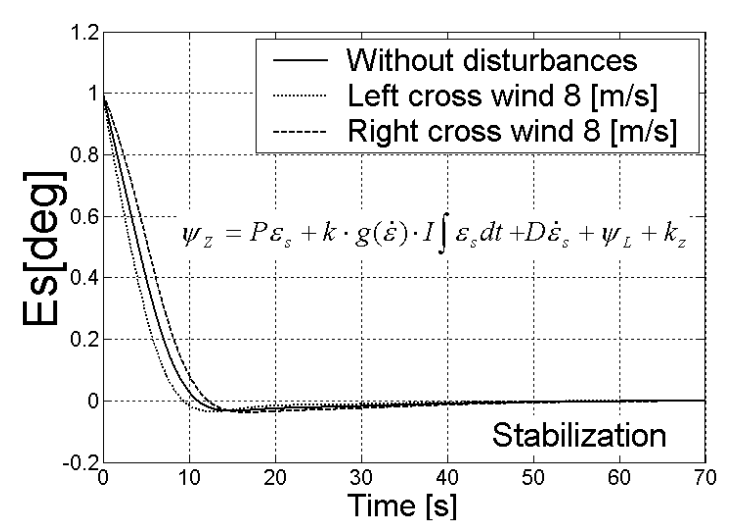

Fig 4b. Simulation results for stabilization with the use of control law 14

The performance index for the solution presented is:

For stabilization: $\quad \mathrm{J}=0.3572$

For whole approach: $\quad \mathrm{J}=10.6$

The analysis of figures 3 and 4 and comparison of the calculated performance indexes 15 and 16 and the performance indexes shown in table 1 clearly prove that the last solution is the best. Because of additional information about the track angle and heading used in the control laws, there are no overshoots and no stabilization errors. 


\section{Improvement of control quality in case of lack of information about track angle and heading with the use of model-following control}

Information about the track angle can be available from a GPS receiver. When this information is not available, the aircraft can be controlled with the use of the control law 11, 12.

A question appears whether it is possible to obtain information about wind from available signals. Indirect information on wind can be obtained through the comparison of the aircraft trajectory without wind with a real trajectory. The trajectory can be calculated from a model consisting of an aircraft model connected with a control system. The difference between the model and the real aircraft trajectory is the information used for the wind compensation [5]. Then instead of integration in LOC regulator, an additional I or PI regulator can be used, as shown in figure 5 .

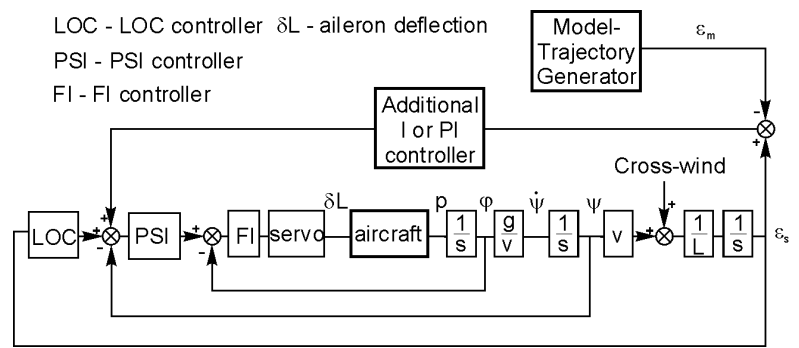

Fig 5. Illustration of the idea of usage model-following control

Unfortunately, simulations proved that the system shown in figure 5 is very sensitive to differences between the aircraft model used for the generation of a trajectory and the "real" aircraft. The smallest differences appear during straight-line flight, so the idea of the control system presented in figure 5 was used during interception. During stabilization, linear quadratic regulator was applied.

\subsection{Linear quadratic regulator}

LQR method enables the use of information on all states for the control [7]. One of the states is the integrated difference between the "real" trajectory and the trajectory generated by the model-trajectory generator. The aircraft, trajectory and classical autopilot (Fig 2), without integration in LOC regulator, and model trajectory generator (Fig 5) were described in one statespace:

$$
\dot{\mathbf{x}}=\mathbf{A} \mathbf{x}+\mathbf{B u}
$$

Where:

$\mathrm{x}-\mathrm{n}$-dimension vector of states, $n=14$,

$\mathrm{u}-\mathrm{m}$-dimension vector of control, $m=n=14$,

A - state matrix,

$\mathrm{B}-$ input matrix.

It is assumed that all states are measured:

$$
\mathbf{y}=\mathbf{x}=\left[x_{1}, x_{2}, \ldots, x_{14}\right]^{T}
$$

Where:

Measured states:

$x_{1}=\varepsilon_{s}-$ see def. in fig. 1 ,

$x_{2}=\psi-$ aircraft heading,

$x_{3}=\phi-$ aircraft bank angle,

$x_{4}=p-$ roll rate,

$x_{5}=\delta L-$ aileron deflection angle,

$x_{6}-$ servo internal state.

States calculated inside model-trajectory generator:

$x_{7}=\underline{x}_{1}=\varepsilon_{m}-$ calculated angle of approach,

$x_{8}=x_{2}=\psi$ - calculated heading,

$x_{9}=x_{3}=\underline{\phi}-$ calculated bank angle,

$x_{10}=\underline{x}_{4}=\underline{p}-$ calculated roll rate,

$x_{11}=\underline{x}_{5}=\underline{\delta L}-$ calculated deflection,

$x_{12}=\underline{x}_{6}-$ calculated servo internal state.

Additional states:

$x_{13}=x_{e l}=\int\left(\varepsilon_{s}-\varepsilon_{m}\right) d t-\quad$ integrated difference

between real and calculated trajectory,

$x_{14}=x_{e 2}=\varepsilon_{s}-\varepsilon_{m}-$ difference between real and calculated trajectory.

$L Q R$ control law is as follows:

$$
\mathbf{u}=-\mathbf{K x}
$$

Where $\mathrm{K}$ - vector of feedback from all described states.

To calculate $\mathrm{K}$, the performance index is minimized:

$$
J_{M F C}=\frac{1}{2} \int_{0}^{\infty}\left(\mathbf{x}^{T} \mathbf{Q} \mathbf{x}+\mathbf{u}^{T} \mathbf{R} \mathbf{u}\right) d t
$$

Where:

matrix,

$\mathrm{Q}$ - symmetric positive semi-definite weighting

$\mathrm{R}$ - positive definite weighting matrix.

For calculations, the following was assumed:

$\checkmark \quad$ aircraft dynamics are described by rolling mode;

$\checkmark$ model-trajectory generator is the same as "real" aircraft+trajectory+control systems;

$\checkmark$ system is linear (without limitations);

$\checkmark$ LOC regulator (figure 1) is based on proportional regulator.

Weighting matrices $\mathrm{Q}$ and $\mathrm{R}$ were chosen in such a way as to minimize only states $x_{13}$ and $x_{14}$ :

$$
Q_{13,13}=Q_{14,14}=5
$$

all other elements of matrix $Q$ are zero,

$$
R=2
$$

Vector K was calculated with the use of Matlab.

\subsection{Simulations of stabilization}

The scheme of the simulation model is presented in figure 6. Elements of feedback vector from all states are marked with a dashed line. It was assumed that the "real" aircraft is described by equations (4) and (5). For 
the aircraft's dynamic model in the model-trajectory generator, equation (8) was used. Simulations proved that the quality of control is satisfactory if the initial heading related to approach axis is about 30 degrees. Quality of control is good if the time of regulation for the "real" aircraft is the same as the time of regulation in the modeltrajectory generator. Quality of control is also good if the regulation time of the model-trajectory generator is slower than the regulation time of the "real" aircraft.

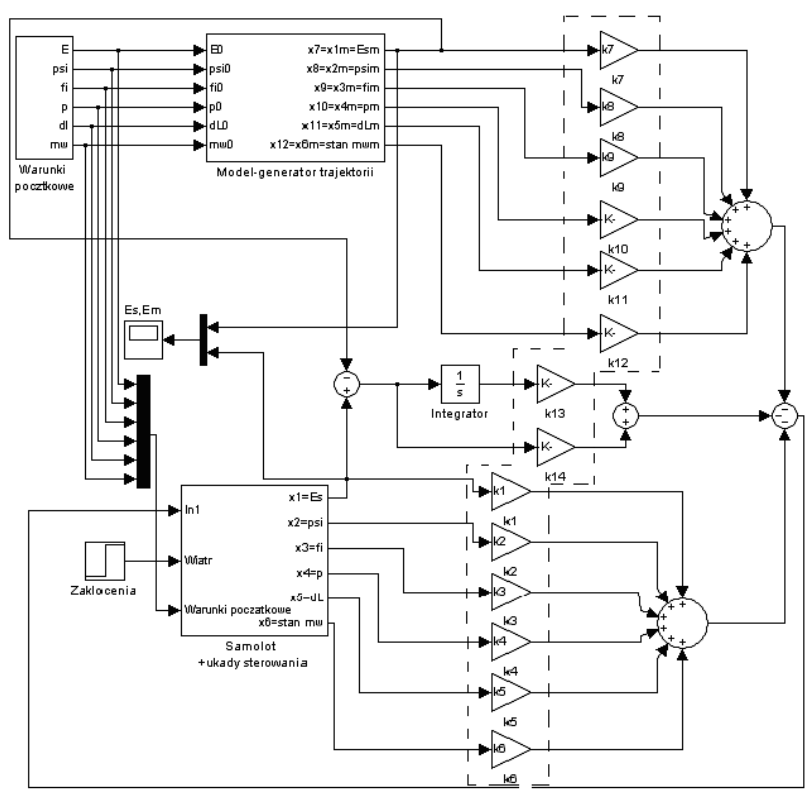

Fig 6. Simulation scheme for stabilization with the use of model-following control

\subsection{Analysis of control quality of model- following control during approach}

Simulations were made as follows:

$\checkmark$ Desired heading was equal to track angle during interception;

$\checkmark \quad$ When heading was equal to desired heading, the control during interception was in accordance with the idea presented in figure 5;

$\checkmark$ Stabilization was in accordance with control scheme presented in figure 6 (LQR control law).

The following limitations were considered:

$\checkmark \quad$ Limitation of desired heading (30 deg) related to axis of approach;

$\checkmark$ Limitation of desired interception angle (25 deg);

$\checkmark \quad$ Limitation of desired aileron angle displacement (30 deg);

$\checkmark$ Limitation of aileron displacement angular velocity $(45 \mathrm{deg} / \mathrm{s})$.

The same limitations were also considered in the modeltrajectory generator. The results are presented in figure 7.

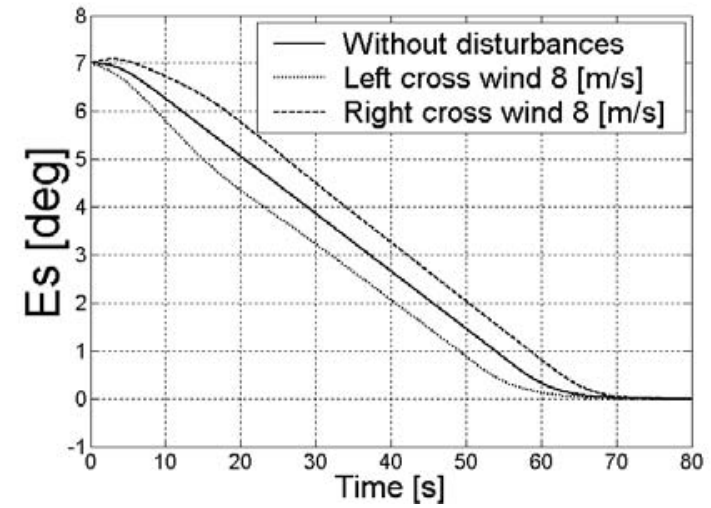

Fig 7a. Simulation results with the use of model-following control - approach

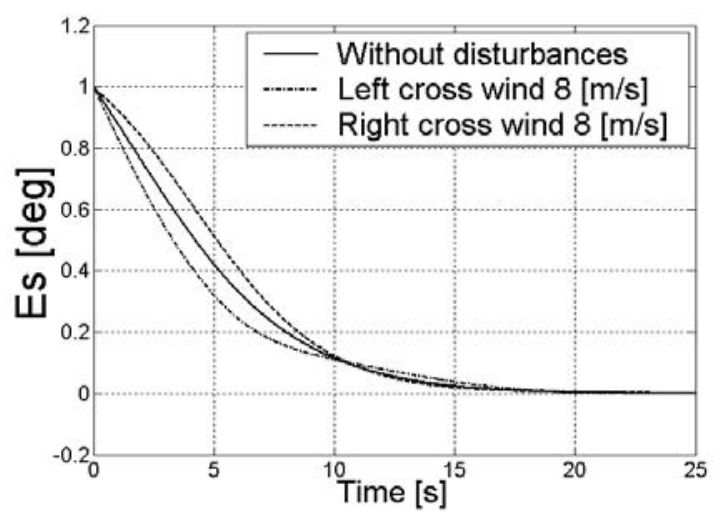

Fig 7b. Simulation results with the use of model-following control- stabilization

Calculated performance index:

$$
J=0.1033\left[\operatorname{deg}^{2}\right]
$$

for stabilization only:

$$
J=0.04471\left[\mathrm{deg}^{2}\right]
$$

The analysis of figure 7 and comparison of calculated performance indexes (23) and (24) with performance indexes calculated earlier, proves that control quality is similar to control quality of the system with control laws (12) and (13), where track angle is measured.

\section{Control quality in case of wind turbulences}

\subsection{Sine wave wind turbulence}

All control laws for stabilization were tested for sine wave wind turbulence. For the wind model, sine waves were used with an amplitude of $5 \mathrm{~m} / \mathrm{s}$ and frequencies of $0.1 \mathrm{rd} / \mathrm{s}, 0.25 \mathrm{rd} / \mathrm{s}, 0.5 \mathrm{rd} / \mathrm{s}, 1 \mathrm{rd} / \mathrm{s}, 4 \mathrm{rd} / \mathrm{s}$, and $8 \mathrm{rd} / \mathrm{s}$.

For control laws testing, performance index (25) was used:

$$
J=\int\left(\varepsilon_{s}-\varepsilon_{m}\right)^{2} d t
$$

Results are presented in figure 8 and table 2 . 


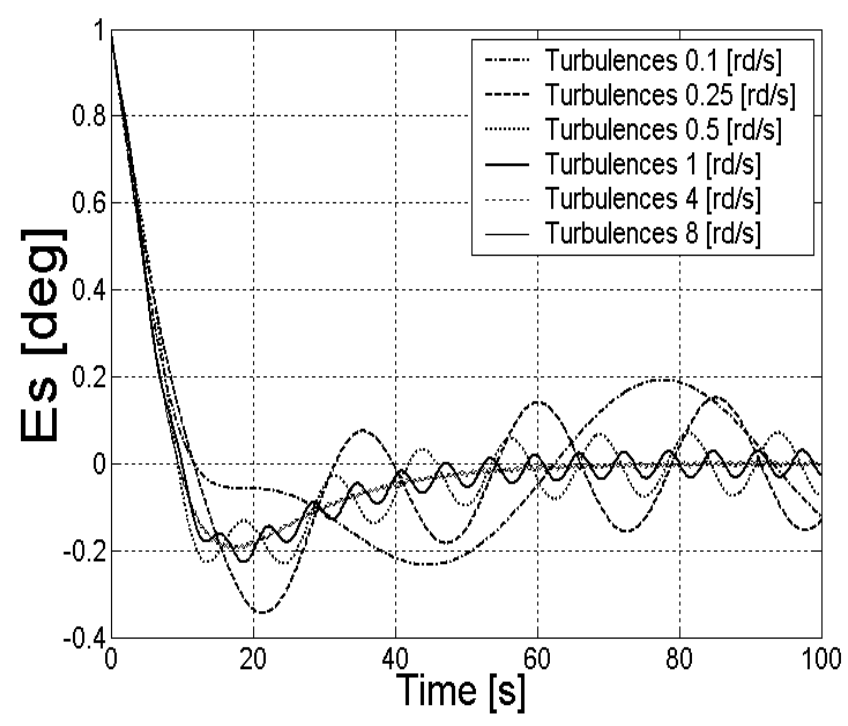

Fig 8a. Influence of turbulence with the use of PID controller

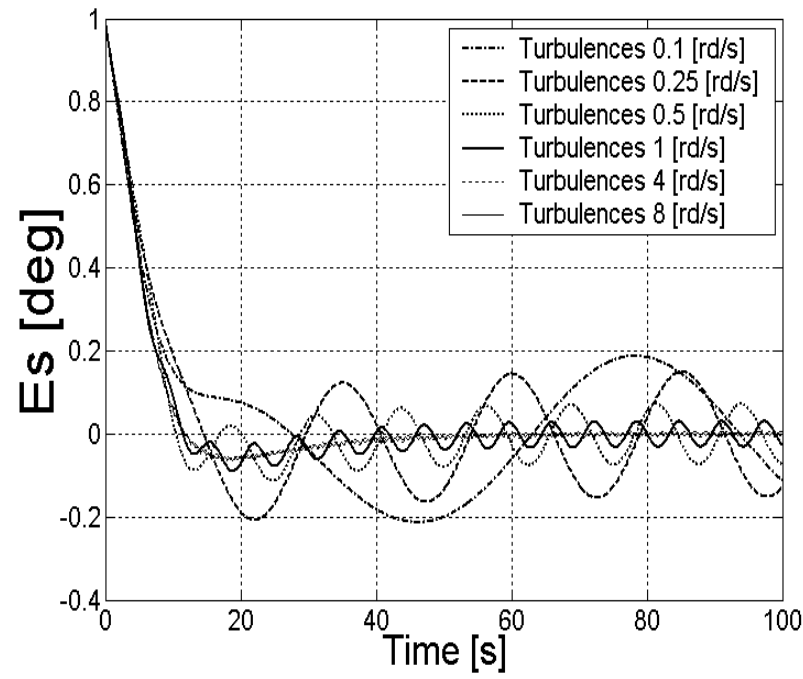

Fig 8b. Influence of turbulence with the use of control law (10)

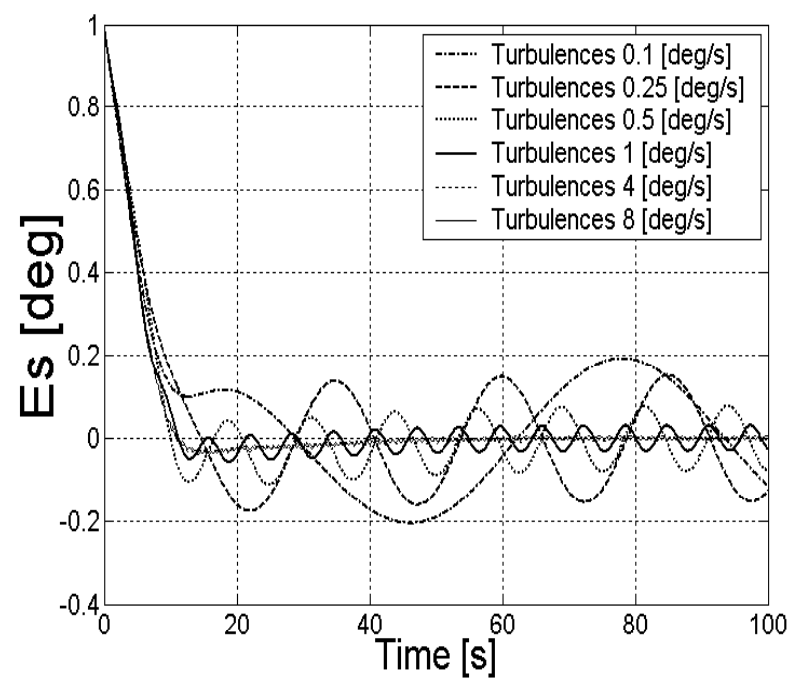

Fig 8c. Influence of turbulence with the use of control law (12)

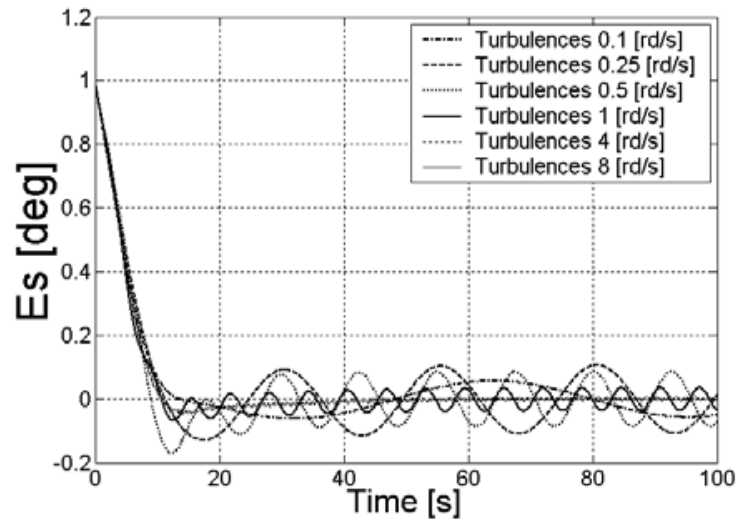

Fig 8d. Influence of turbulence with the use of control law (14)

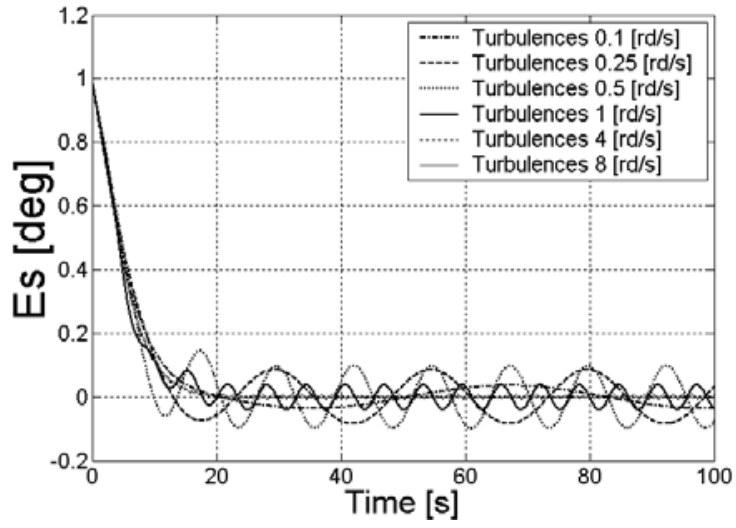

Fig 8e. Influence of turbulences with the use of modelfollowing control (LQR controller)

Table 2. Values of performance index

\begin{tabular}{|l|l|l|l|l|l|}
\hline $\begin{array}{l}\text { Freque } \\
\text { ncy } \\
{[\mathrm{rd} / \mathrm{s}]}\end{array}$ & $P I D$ & $\begin{array}{l}\text { Control } \\
\text { law 10 }\end{array}$ & $\begin{array}{l}\text { Control } \\
\text { law12 }\end{array}$ & $\begin{array}{l}\text { Control } \\
\text { law14 }\end{array}$ & MFC (LQR) \\
\hline 0.1 & 1.715 & 1.452 & 1.435 & 0.1562 & 0.07494 \\
\hline 0.25 & 1.936 & 1.177 & 1.089 & 0.5578 & 0.3238 \\
\hline 0.5 & 0.9805 & 0.3186 & 0.3721 & 0.5345 & 0.5043 \\
\hline 1 & 0.7002 & 0.1042 & 0.07874 & 0.1153 & 0.0868 \\
\hline 4 & 0.618 & 0.05946 & 0.04127 & 0.05071 & 0.006155 \\
\hline 8 & 0.6104 & 0.05794 & 0.03907 & 0.0478 & 0.0042 \\
\hline
\end{tabular}

As we can see in table 2, control quality depends on the frequency of wind turbulence. In all cases, the classical PID controller was the worst one. For low frequencies, the best control quality ensured by control law 14 and 19 (LQR). For high frequencies, control quality in the system based on control law 14 is worse than with control law 12 (without information about heading and track angle). But we can see that high frequencies are very well damped in all cases with the use of all control laws. It shows that control laws 14 (modified PID, with integration coefficient dependent on $\left.\frac{d \varepsilon_{s}}{d t}\right)$ and 19 (model-following control) are the best for stabilization. 


\subsection{Dryden's atmospheric turbulence model}

All control laws for stabilization were tested for Dryden's wind turbulence model [1], [6]. Simulated wind velocity is presented in figure 9. For control laws testing, performance index (25) was used. The results of simulations are presented in figure 10. The values of the calculated performance index are shown in table 3 .

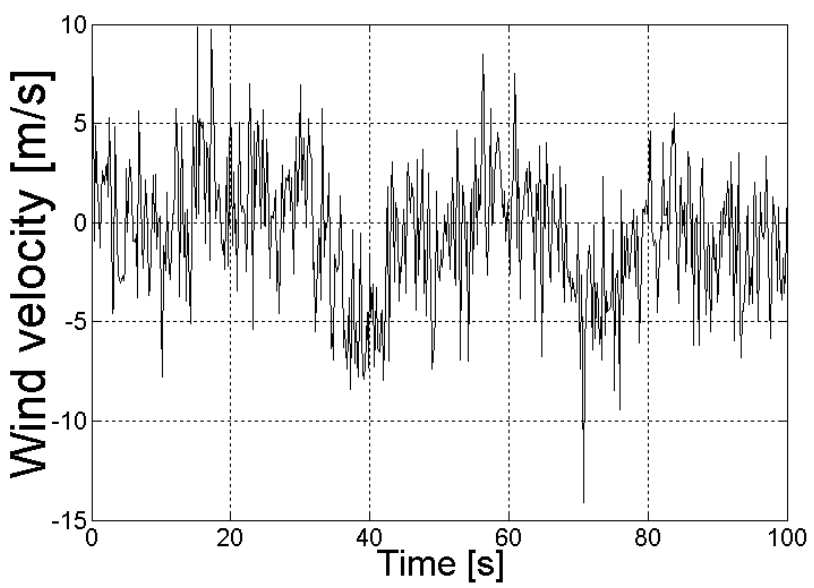

Fig 9. Simulated wind velocity

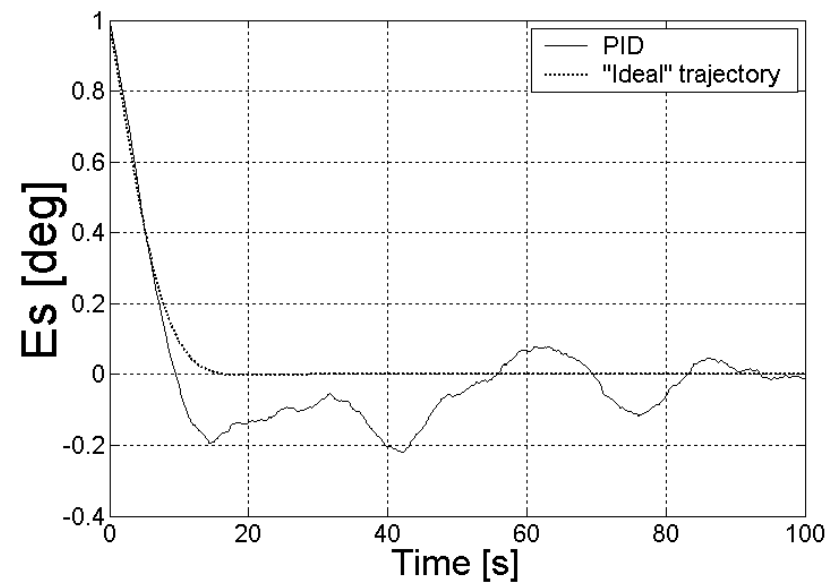

Fig 10a. Influence of turbulence with the use of PID LOC controller

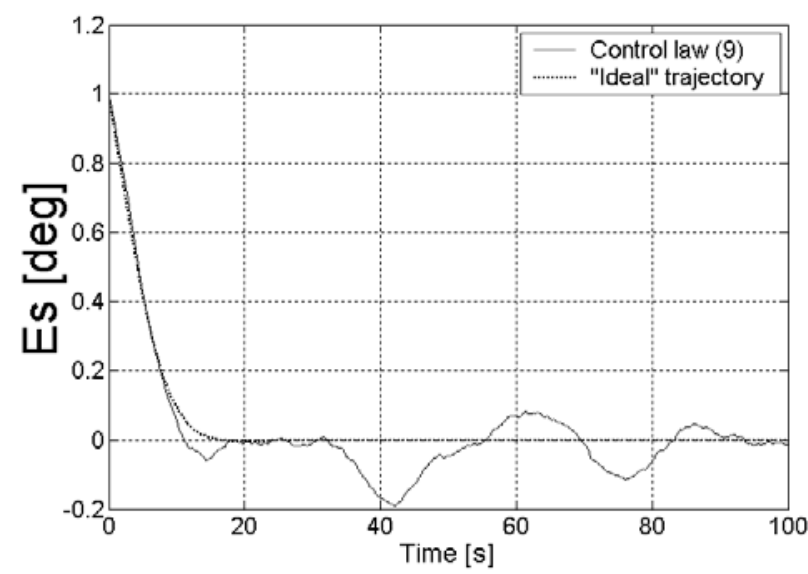

Fig 10b. Influence of turbulence with the use of control law (9)

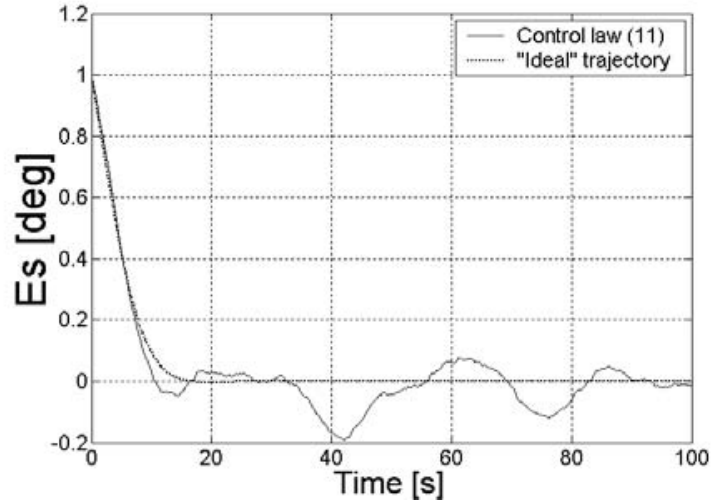

Fig 10c. Influence of turbulence with the use of control law (11)

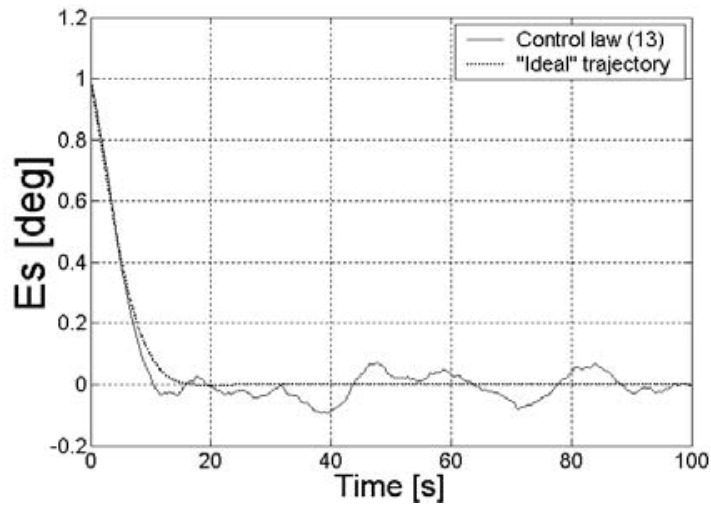

Fig 10d. Influence of turbulence with the use of control law (13)

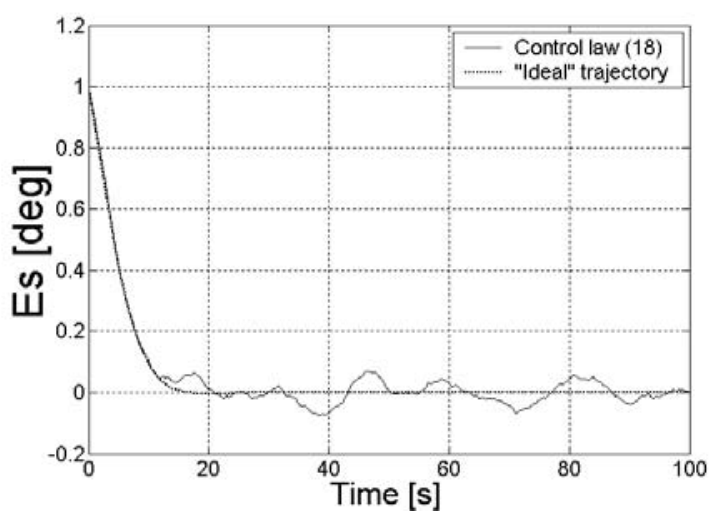

Fig 10e. Influence of turbulence with the use of control law (18)

Table 3. Values of performance index (24)

\begin{tabular}{|l|l|l|l|l|l|}
\hline & PID & $\begin{array}{l}\text { Control } \\
\text { law 9 }\end{array}$ & $\begin{array}{l}\text { Control } \\
\text { law11 }\end{array}$ & $\begin{array}{l}\text { Control } \\
\text { law13 }\end{array}$ & $\begin{array}{l}\text { MFC } \\
(\text { LQR })\end{array}$ \\
\hline Value & 0.943 & 0.4004 & 0.4083 & 0.1745 & 0.1008 \\
\hline
\end{tabular}

An analysis of figures 10 and and values of the integration coefficient presented in table 3 again proves, that the best quality of control is with the use of control law 14 (modified PID, with integration coefficient dependent on $\frac{d \varepsilon_{s}}{d t}$ ) and 19 (model-following control). 


\section{Conclusions}

This article discusses the synthesis and analysis of a control system for aircraft approach with the use of different control laws. The control quality was assessed with the use of a performance index. It is impossible to use the same index for the assessment of all disturbances. Consequently, different performance indexes were applied for constant cross wind and for turbulence. All results compared were simulated with the same conditions (time of simulation and initial conditions).

For the assessment of control quality without turbulence and with constant crosswind, the performance index (1) was used. The results are presented in table 1 . The best control quality for these conditions was obtained using control laws (13), (14) (modified PID controller with additional information about heading and track angle) and for model-following control.

For the assessment of control quality during stabilization with sine turbulence and Dryden's model, the performance index (25) was used. Different frequencies of wind turbulences were tested. The results are presented in table 2. For low frequencies, the best control laws were the same as those for constant wind. For high frequencies, control quality with control laws (14) (with information about heading and track angle) and (19) (model-following control) was worse than with the control laws based on modified PID. But the aircraft very well damps those frequencies and their influence is very low. For Dryden's model turbulences, the best control quality was with the use of control laws (14) and (19). Figures 3, 4, 7, 8 and 9 prove that the best control quality in general case is ensured by control laws 13,14 (modified PID, with integration coefficient dependent on $\frac{d \varepsilon_{s}}{d t}$ ). In case of lack of information about the track angle, the best control quality is ensured by control based on the idea presented in figure 5 and control law 19 (model-following control).

Real tests of these control laws will be carried out after their implementation in an autopilot and after flight tests.

\section{References}

1. Bociek S., Gruszecki J. Układy sterowania automatycznego samolotem. - Rzeszów: Oficyna Wydawnicza Politechniki Rzeszowskiej, 1999. - P. 231-261.

2. Helfrick A.D. Modern Aviation Electronics. New Jersey: Prentice-Hall, Inc, 1994. - P. 189208.

3. Etkin B. Dinamika polota. - Moscow: Maszynostrojenie, 1964.

4. Kopecki G. Analiza jakości sterowania podejściem do lądowania przy zastosowaniu klasycznych praw sterowania // Rzeszów: Mechanika. - 2004. - Z. 63. - P. 109-116.

5. Kopecki G. Analiza jakości sterowania podejściem do lądowania przy zastosowaniu sterowania według modelu // Ibid. - P. 117-124.

6. Rogalski T. Projekt mikrokomputerowego stoiska symulacyjnego do badania systemów sterowania i nawigacji dla bezzałogowych aparatów latających: Master's thesis. Rzeszów: Rzeszów University of Technology, Faculty of Mechanical Engineering and Aeronautics, Departament of Control Systems, 1996.

7. Stevens B. L., Levis F. L. Aircraft Control and Simulation. - New York: John Willey \& Sons, Inc., 1992. 